\title{
Buckling behavior of double-skin composite walls: an experimental and modeling study
}

\author{
Yang Yue, Liu Jingbo, Fan Jiansheng \\ Key Laboratory of Civil Engineering Safety and Durability of China Education Ministry, Department of Civil \\ Engineering, Tsinghua University, Beijing 100084, China
}

\begin{abstract}
Double-skin composite (DSC) panels can offer high strength and robustness while improving the convenience of construction, with great potential for application in high rise buildings and nuclear power plants. In DSC panels, the stability of the outer surface steel plates are governed by the constraints of the in-fill concrete and the discrete shear connectors, i.e., the ratio of connector spacing $(B)$ and surface steel plate thickness $(t)$. In this paper, tests were performed on 10 specimens to assess the buckling behavior of DSC panels. The arrangement of the shear studs and the $B / t$ ratio were varied in the tests. The results show that the arrangement and spacing of the shear studs can considerably influence the buckling shapes and loading capacity of the steel plates. Three-dimensional finite element (FE) models were developed to simulate the behavior of DSC panels subject to compression, and the FE results were found to be in good agreement with the observed buckling behavior during tests. A theoretical model based on Euler's equation was also proposed to predict the buckling stress of steel plates, and it showed reasonable agreement with the experimental measurements and FE results.
\end{abstract} The formula proposed in this paper can be used for determining the number or spacing of shear studs in DSC walls.

Keywords: double skin composite panels; buckling; axial compression; shear stud arrangement; FE analysis

\section{Introduction}

DSC panels consist of two steel plates and in-fill concrete, combined to work compositely using mechanical connectors such as shear studs or tie bars. With the constraints of the in-fill concrete and the regularly spaced connectors, the stability of the surface steel plate is enhanced greatly [1]. Moreover, the brittleness of the concrete is also improved. DSC structures also exhibit superior characteristics in impermeability and impact resistance [2, 3]. 
DSC panels provide high efficiency in construction practice with the steel plates prefabricated in factory and assembled on-site. Compared with reinforced concrete structures, formwork is avoided. Given these advantages, DSC structures demonstrate notable competitiveness in under-sea tunnels, nuclear power plants, and high-rising buildings $[4,5]$.

When DSC panels sustain axial compression or out-of-plane bending, the surface steel plate between connectors is constrained by the rigid concrete on one side and may buckle outwards, reducing the load capacity and stability of the structure. The ratio of the spacing between connectors $(B)$ and the steel plate thickness $(t)$ is the key factor governing the buckling of the steel skins. Akiama et al. [6] proposed the buckling stress of a surface plate according to test results as follows:

$$
\sigma_{\mathrm{cr}}=\frac{\pi^{2} E_{\mathrm{s}}}{12 K^{2}(B / t)^{2}}
$$

where $K$ is the effective length factor and equals 0.7 .

Let $\sigma_{\mathrm{cr}}=f_{\mathrm{y}}$, then the critical $B / t$ ratio for buckling before yielding can be derived as:

$$
\frac{B}{t} \leq 1.30 \sqrt{\frac{E_{\mathrm{s}}}{f_{\mathrm{y}}}}
$$

Using the principle of virtual work, Wright [7] established the formula for buckling stress of a steel plate constrained by concrete on one side. By assuming the buckling shape modes, the critical $B / t$ ratio is given as:

$$
\frac{B}{t} \leq 1.90 \sqrt{\frac{E_{\mathrm{s}}}{f_{\mathrm{y}}}}
$$

Many experiments have been performed to study DSC walls [8-11], but only limited measurements have focused on buckling behavior [12-15]. The parameters studied in such experiments include the $B / t$ ratio and steel strength. Kai et al. [16] developed finite element (FE) models of DSC panels and calibrated these models with laboratory test results reported in the literature [12]. Based on a parametric study, the critical $B / t$ ratio is given as: 


$$
\frac{B}{t} \leq 1.0 \sqrt{\frac{E_{\mathrm{s}}}{f_{\mathrm{y}}}}
$$

On the basis of the stationary potential principal, Nie and Li [17] proposed the local buckling stress for the surface steel plate, with the critical $B / t$ ratio given as:

$$
\frac{B}{t} \leq 1.03 \sqrt{\frac{E_{\mathrm{s}}}{f_{\mathrm{y}}}}
$$

The above formulas have similar expressions but different coefficient values. The energy methods provide meaningful physical models but their accuracy depends on the assumed boundary conditions and buckling shape functions. The empirical method based on experimental results can account for the influence of initial imperfections and the welding residual stress, but the accuracy depends on the number of laboratory tests, which are expensive and time-consuming. In most previous experiments on DSC panels, the $B / t$ ratio was less than 50 , but results with larger $B / t$ values are also valuable to understand elastic buckling. Further, the connector arrangement also affect the buckling behavior of surface plates, and the effectiveness of such arrangements needs to be tested and evaluated.

Apart from experiments, many numerical methods have been adopted to study the unilateral buckling of steel plates $[18,19]$. In these studies, initial imperfections, slip at the steel-concrete interfaces, and support conditions have been investigated, and the conclusions compared with theoretical and experimental results.

In this paper, a series of experimental tests was conducted on DSC walls subjected to axial forces. FE models of the DSC specimens were also developed and calibrated with the test data. The objectives of this study were 1) to provide experimental data and FE analysis results for steel plate buckling behavior by considering the influences of connector arrangement, $B / t$ ratio, tensile stiffness of shear studs, and initial imperfections and 2) to propose more reasonable limits to the $B / t$ ratios. 


\section{Test Specimens}

Ten DSC panel specimens were designed and tested. All the specimens had the same geometry: width $=1200$ $\mathrm{mm}$, height $=1200 \mathrm{~mm}$, and total thickness (including surface steel plate) $=240 \mathrm{~mm}$. The three parameters considered in the experiments were 1) surface plate thickness, 2) stud spacing, and 3) the arrangement of connectors. The thickness of the surface steel plates was $4 \mathrm{~mm}$ and $6 \mathrm{~mm}$, respectively. Shear studs with diameter 5 $\mathrm{mm}$ and height $35 \mathrm{~mm}$ were welded onto the $4 \mathrm{~mm}$ surface steel plates, and studs with diameter $10 \mathrm{~mm}$ and height $75 \mathrm{~mm}$ were welded onto the $6 \mathrm{~mm}$ plates. The top plate, side plate and bottom plate welded around the surface plate had thickness $12 \mathrm{~mm}$ for all specimens. Fig. 1 shows a schematic of a typical test wall. Details of the specimens are summarized in Table 1 in which $\mathrm{B} / \mathrm{t}$ is calculated with the studs spacing in the vertical (or loading) direction.

The steel plates in the specimens were made of Q345B steel (equivalent to American A36 steel plates). The elastic modulus of the steel was $2.06 \times 10^{5} \mathrm{MPa}$. The characteristics of the steel used for the specimens are shown in Table 2, where $f_{\mathrm{y}}$ is the lower yielding strength. The in-fill concrete in the DSC specimens was of grade C40, with a nominal cubic compressive strength of $40 \mathrm{MPa}$ and actual cubic compressive strength $f_{\text {cu }}$ listed in Table 1 .

The instrumentation employed in the experiments included strain gauges placed on the surface of the steel plates and linear variable differential transformers (LVDTs) placed vertically on the side of the specimen panels. No attempt was made to measure the horizontal separation and slip between the steel plate and the in-fill concrete.

\section{Loading process and failure mode}

The specimens were tested using $20000 \mathrm{kN}$ loading equipment in the Structural Engineering Lab of Tsinghua University. First, the tests were performed under force control with a force increment of $500 \mathrm{kN}$. When the specimens reached the yield point, the loading process changed to displacement control. The loading process was 
stopped after the load decreased noticeably as a result of the buckling of the steel plate and crushing of the concrete.

During the loading process, the compression stress of the steel plate increased continually with the axial force. When the stress reached a critical value, the steel plate between the shear studs buckled because of the insufficient constraint. The buckled steel plates lost their support capacity with increasing lateral deformation. The compression on the steel plates was then transferred to the in-fill concrete through the shear force at the steel-concrete interfaces provided by adjacent shear studs, and the stress was redistributed in the composite cross-section. When the specimens reached the ultimate loads with crushing of the in-fill concrete, buckles in the surface plates were obvious. At the ultimate stage, rupture or pull-out of the shear studs also occurred during the large plate deformation and crushing of the concrete.

The tests indicated a brittle failure mode with small compression deformation. The steel plates sustained compression force in the early loading stage but lost load capacity after buckling occurred. As no tie bars or diaphragms were applied in the specimens, confinement of the in-fill concrete provided by the outer steel plates was negligible.

For specimens with a square arrangement of studs, outward buckling occurred between the two rows of connectors. The expansion of concrete pushed the steel plate outward, which also increased the buckling. At the ultimate stage, the concrete was crushed adjacent to the buckles on steel plates. Fig. 3 shows a typical failure mode of specimens with a square stud arrangement, in specimen DSC6-240. Shear studs were located at the intersection of the grids marked at the surface of specimens. As the buckling was affected by residual stress and initial imperfections, the position of the buckles was random. After the test, crushing of the concrete and fracture of the studs was observed by peeling away the steel skin. The inner surface of the steel plate after fracture of the studs was shown in Fig. 3d. 
Compared with DSC4-300, the specimen with a vertical rectangular stud arrangement (DSC4-150/300) had reduced spacing in the horizontal direction (Fig. 4). With the increased constraint provided by the studs at these discrete points, the steel plates between two rows of adjacent studs sustained a higher buckling stress.

Compared with DSC4-300, the specimen with studs with a horizontal rectangular arrangement (DSC4-300/150) had reduced spacing in the vertical direction (Fig. 5). The reduced spacing of shear studs along the compression direction effectively increased the constraint of the steel plates.

The shear studs in DSC4-300X were welded in a staggered arrangement, which corresponded to the DSC4-300 pattern rotated by 45 degrees. The circles in Fig. 6 show the stud positions. Due to manufacturing error, two types of studs were welded in the specimens: studs with diameter $10 \mathrm{~mm}$ at rows 2 and 4; and studs with diameter $5 \mathrm{~mm}$ at rows 1,3 , and 5 . The anchorage capacities of these two stud types varied greatly. With the increased unilateral buckling the $\phi 5$ studs ruptured or pushed out. Thus, the final buckles in DSC4-300X were spread across a relatively large range, and the buckles were constrained only at the discrete point of the $\phi 10$ studs. It is reasonable to expect that if sufficient anchorage were provided by the studs at rows 1,3 , and 5 , the buckling stress of the specimen would be increased.

\section{Test results and analysis}

\subsection{Load versus displacement}

Fig. 7 presents the load-displacement curves for the tests. For the local compression generated by the uneven surface of the DSC walls, some of the specimens (DSC4-250, DSC4-300, and DSC6-240) showed relatively lower stiffness at the initial loading stage. With an increase in the load, the gaps between the specimens and test machines were eliminated, reaching a stage for which there was a linear relationship between load and displacement. The slope of the curves is assumed to be the axial compression stiffness of the specimens. Specimens with the same 
steel thickness showed similar behavior before reaching the maximum load, and this behavior was not affected by the spacing and arrangement of the shear studs.

The definition of buckling force is illustrated later in this paper and is shown by circles in the upward portions of the curves. DSC6-300 presents a characteristic of the limit load instability, so there isn't an obvious buckling load. After the buckling of the surface plates, the slope of the curves changed slightly, indicating that local buckling did not have a great effect on axial stiffness.

It can be shown from Table 3 that the ratio of the buckling load and the ultimate load of each specimen varies from 0.34 to 0.76 . To study the influence of the buckling behavior of the steel plate on the axial stiffness of the specimens, two values of secant stiffness for each specimen are thus evaluated, the first one takes $0.3 \mathrm{Pu}$ as the start point and the buckling load as the end point, while the second one takes $0.3 \mathrm{Pu}$ as the start point and $0.8 \mathrm{Pu}$ as the end point. As is seen from the last row of Table 3, there is no obvious stiffness deterioration happened after buckling except for specimen DSC6-360, which also means the axial stiffness remains the same after buckling.

The ultimate axial loading strength of the DSC walls after buckling of the surface steel plates is given as:

$$
N_{\mathrm{u}}=f_{\mathrm{c}} A_{\mathrm{c}}+f_{\mathrm{y}} A_{\text {side }}
$$

where $A_{\text {side }}$ is the area of the two side steel plates.

Comparisons between the calculated and test results are provided in Table 4. The internal forces of the side steel plates are also listed in the table. The last column in Table 4 is the residual strength of the specimens after the crushing of the concrete, which was approximately $40 \%$ to $60 \%$ of the ultimate strength.

\subsection{Buckling stress}

When the DSC walls were loaded under axial forces, the surface steel plate buckled between two adjacent rows of shear studs. However, the presence of in-fill concrete prevented any buckling in the inward direction. Unilateral local buckling is fundamentally different from bilateral local buckling, which often occurs in pure steel 
plate shear walls. In specimens with square or rectangular stud arrangements, the steel plates buckled horizontally with half-waves, as shown in Fig. 8. Strain rosettes were used to monitor the strain development of the steel plates. The $0^{\circ}$ and $-90^{\circ}$ gauges corresponded to the horizontal and vertical directions, respectively. The locations of the gauges are shown in Fig. 8 and Fig. 9.

The measured vertical strains at positions A and B are illustrated in Fig. 10, in which the two curves are very close before buckling. After buckling, the steel plate at position A buckled outward, and the strain changed from compression to tension. Meanwhile, the strain at position B increased quickly due to the local bending of the surface plate. The inflection points of the two strain curves appear to be almost under the same load. The buckling load can be obtained based on the inflection points of the strain curves.

Specimen DSC4-300/150 showed a higher buckling stress than DSC4-150, with a buckling strain of $-1114 \times 10^{-6}$ at point A (Fig. 10f). Its buckling strain was about twice that of Specimen DSC4-150, which had more restraint from shear connectors. Despite the lower number of shear connectors on DSC4-300/150, the higher buckling stress could be explained by fewer defects in the manufacturing process compared with DSC4-150.

Specimen DSC4-300X had a staggered connector arrangement. The maximum lateral displacement of the surface plate also occurred between two rows of shear connectors at point A shown in Fig. 9(b). According to the strain measurement depicted in Fig. 10(g), an inflection point was found on the strain curve at point A, while it didn't appear at point B, which indicates the buckled shape was constrained by staggered studs.

The strain development of DSC6-300 showed no obvious inflection points in the curves (Fig. 10i). The compression strain at point A changed to tension during the early loading stage due to the relatively large initial curvatures generated during the manufacturing, transportation, or concrete pouring processes. Thus the specimen presents a characteristic of the limit load instability.

According to the strain measurement, vertical compression, lateral tension, and shear stress all existed in the 
surface steel plate. Marking the inflection point as an indicator of local instability, the buckling stress can be determined by equations (4) (6) using the strain measured at points A and B. Additionally, it should be noted that equations (4) (6) are valid for both elastic and plastic behavior.

$$
\begin{gathered}
\sigma_{\mathrm{v}}=\frac{E}{1-\mu^{2}}\left(\varepsilon_{0^{\circ}}+\mu \varepsilon_{-90^{\circ}}\right) \\
\sigma_{1}=\frac{E}{2}\left[\frac{\varepsilon_{0^{\circ}}+\varepsilon_{-90^{\circ}}}{1-\mu} \pm \frac{1}{1+\mu} \sqrt{\left(\varepsilon_{0^{\circ}}-\varepsilon_{-90^{\circ}}\right)^{2}+\left(2 \varepsilon_{-45^{\circ}}-\varepsilon_{0^{\circ}}-\varepsilon_{-90^{\circ}}\right)^{2}}\right] \\
\sigma_{0}=\sqrt{\sigma_{1}^{2}+\sigma_{2}^{2}-\sigma_{1} \sigma_{2}}
\end{gathered}
$$

where $E$ is the Young's modulus of steel and $\mu$ is the Poisson's ratio.

The critical buckling stresses of the test specimens calculated using the above equations are listed in Table 5 .

Fig. 11 shows the critical buckling stress against the $B / t$ ratios for all specimens, where the solid marks represent specimens with a square arrangement of studs and the hollow marks represent the other specimens. It can be observed that the difference between the von Mises stress and the vertical stress of DSC4-300X is greater than that in the other specimens. This can be explained by the fact that for specimens with a staggered arrangement of shear studs, the diagonal buckling generated larger shear stresses in the surface plates.

The buckling strength of the surface steel plate can be calculated using Eq. (1). That equation was obtained from Euler's equation by substituting the column effective length with $B$, and the effects of the constraints provided by shear connectors were considered by verifying the value of $K$. The values of 1 and 0.7 were used for $K$ for hinged-hinged and clamped-hinged boundary conditions, respectively. The calculated theoretical curves are also presented in Fig. 11.

For specimens with a square shear stud arrangement, the critical buckling stress agreed well with the Euler's curve when $K$ equaled 1 . When the shear studs were arranged as a vertical rectangle, the critical stress increased significantly due to the stronger constraint. For specimen DSC4-300X with a staggered stud arrangement, the vertical buckling stress was close to that of DSC4-300, but the critical von Mises stress increased. This 
phenomenon implies that when using equivalent von Mises stresses to evaluate the stability of the surface plate, the staggered arrangement of shear studs is more favorable than the square arrangement.

Previous studies $[6,12,13,14,15]$ have also considered the compression performance of DSC panels, and the values of $B / t$ varied from 20 to 100. The test results from those studies are plotted in Fig. 12 and compared with the curves predicted using Eq. (1). The results for specimens with $B / t=20$ are omitted in the figure because no buckling was observed before yielding. It can be observed from Fig. 12 that most of the data points are between the two curves corresponding to $K=1$ and $K=0.7$.

To ensure yielding of the steel plate before local buckling, it is reasonably acceptable for practical design purposes to regard the steel plate between the shear studs as compression columns with hinged-hinged boundary conditions. Thus, if we let $K=1$ and $\sigma_{\mathrm{cr}}=f_{\mathrm{y}}$ in Eq. (5), the limit to the $B / t$ ratio is given by the following equation:

$$
\frac{B}{t}=\sqrt{\frac{\pi^{2} E_{\mathrm{s}}}{12 f_{\mathrm{y}}}}
$$

\section{Finite element analysis}

\subsection{FE models}

Numerical analyses were conducted using the FE software package MSC.MARC. The steel plate and in-fill concrete were modeled using shell elements and solid elements, respectively. The surface steel plates were attached to the in-fill concrete via non-linear springs representing the tensile and shear stiffness of the studs. The meshes of the model are shown in Fig. 13

During the nonlinear buckling analysis, initial out-of-plane deformation was required to initiate buckling. In this study, the imperfection shapes were based on the first order eigenvalue buckling mode shapes with the maximum lateral deformation of $1 / 1000$ of the stud spacing. 
The surface steel plates were unilaterally restrained by the in-fill concrete. To simulate the unilateral constraints, contact elements were used between steel plates and concrete. However, the contact elements were only functional when the surface plate contacted the in-fill concrete as a result of inward deformation induced by buckling. The shape of the buckling mode of the steel plates was in the form of unilateral half waves (see Fig. 14), corresponding with the test results.

\subsection{Model Evaluation}

Comparisons with experimental tests were proposed to validate the numerical model. By varying the thickness of the steel plates and the spacing of the shear studs, all the test specimens were modeled and the loading process was simulated. The calculated strain at the maximum lateral deformation position is compared with the test results in Fig. 15.

It can be seen that the shapes of the calculated curves are similar to those of the test results. The calculated maximum compression stresses were higher than the measured ones, because the load eccentricity and the push-out of the shear studs were not considered in the FE model. In Fig. 16, the calculated buckling stresses for specimens with different plate thickness are illustrated and compared with the test results. Comparison with the FE results also shows a good approximation of the theoretical prediction with $K=1$.

\subsection{Parameter study}

The buckling behavior of DSC panels is complex, depending on the arrangement of connectors, the thickness, the initial imperfections of the steel plates, and the magnitude of forces to which the steel plates are subjected. Furthermore, the shear connectors play an important role in confining the surface plates from lateral displacement. FE models were utilized to study this complex buckling behavior by varying different parameters. 


\subsubsection{Effects of tension stiffness of shear studs}

In the FE models, the shear studs were simulated using tension-only springs in the lateral direction. The shear studs would elongate with the buckling of surface plates, and can be considered as elastic supports. The tensile stiffness of the shear studs depended not only on the deformation of the stud itself but also on the anchorage capacity of the concrete surrounding the stud shank and head [20]. To simplify the calculation of this combined stiffness, the equivalent tensile stiffness of the studs was calculated as follows:

$$
K_{\mathrm{st}}=\alpha_{\mathrm{st}} \frac{E_{\mathrm{st}} A_{\mathrm{st}}}{l_{\mathrm{st}}}
$$

where $E_{\mathrm{st}}$ is the Young's modulus of stud material, $A_{\mathrm{st}}$ is the area of the stud shank, $l_{\mathrm{st}}$ is the stud height, and $\alpha_{\mathrm{st}}$ is the coefficient of tensile stiffness which considers the interactions between the studs and concrete.

Fig. 17 illustrates the change in the vertical stress in the steel plate with the compression deformation for different values of stud tensile stiffness. The buckling stress with flexible connectors reduced more significantly than that with rigid connectors. Meanwhile, it is noted that the buckling stress is not sensitive to the coefficient of tensile stiffness when $\alpha_{\mathrm{st}}$ is greater than 0.5 .

The effect of the stud tensile stiffness on the relationship between buckling stress and the $B / t$ ratios is illustrated in Fig. 18. Three levels of stud tensile stiffness were investigated and compared with the Euler's formula. Examination of the curves indicates that the load carrying capacity decreases as the tensile stiffness of the shear studs decreases, but the effects are negligible when $\alpha_{\mathrm{st}}$ is greater than 0.5 .

Most research into the stiffness of shear studs has focused on the shear versus slip relationship, and experimental results for tensile stiffness were not reported. Despite the large number of past research work on shear studs, more studies are needed to evaluate tensile stiffness and the effective factors.

\subsubsection{Effects of stud arrangement}

The effects of stud arrangements on buckling behavior were observed in the experiments, which allowed 
optimization of the connector arrangement. Because of the limited quantity of specimens and the defects introduced in the manufacturing procedure, there was some degree of scatter in the test results. The effects of stud arrangements were further studied using the FE method.

Fig. 19 indicates the different stud arrangements that were analyzed and examined. The control model FE150 had a square arrangement with stud spacing of $150 \mathrm{~mm}$ in both two directions. In models FE75-150 and FE300-150, the stud spacing perpendicular to the compression direction was changed to 75 and $300 \mathrm{~mm}$, respectively. In model FE150X, the shear studs were rotated by 45 degrees compared with the control model. Numerical results for the buckling stress of the surface steel plates with different stud arrangements are presented in Fig. 20. The results show that the buckling stress had a direct relationship to the stud arrangement.

FE75-150 generates half-wavelengths of the unilateral buckling in the vertical direction. The lateral deformation extends in the horizontal direction and forms buckles between two rows of shear studs, which are similar to that of FE150. With the decreased spacing of the shear studs in the horizontal direction, a larger buckling force is necessary compared to FE150. FE300-150 shows a buckling mode that is different from that in FE150, but the buckling stress is nearly the same. FE150X also shows a different buckling mode, with more buckling waves but smaller wavelengths, in turn implying a higher buckling force. Therefore, it can be concluded that for DSC panels under uniaxial compression, the use of shear studs in a staggered arrangement is more efficient than that with a square arrangement.

\subsubsection{Effects of initial geometrical imperfections}

Initial imperfections in DSC panels usually result from the steel fabrication and concrete pouring process. Because the specimen panels were not made to full scale and the welding procedures were different from those in production workshops, the effects of initial imperfections were appropriately determined using FE methods. Only one type of initial geometrical imperfection was accounted for in this study, namely out-of-plane imperfections in 
the surface steel plate. Imperfections in the shear studs and in-fill concrete were not considered.

The initial imperfection was defined by the magnitude of the maximum out-of-plane deflection with the shear stud spacing $B$ as:

$$
\Delta_{\mathrm{s}}=\beta_{\mathrm{s}} B
$$

where $\beta_{\mathrm{s}}$ is the initial geometrical imperfection factor.

The effect of the magnitude of initial imperfections on FE150 is presented in Fig. 21. The analysis is performed for initial imperfection magnitudes ranging from B/10000 to B/200. Fig. 21 shows that the magnitude of initial imperfections had a very significant effect on the ability of the DSC panels to carry axial load, and the figure can be used to estimate the buckling stress.

\section{Conclusions}

Laboratory tests and finite element analysis were performed to evaluate the buckling performance of DSC panels under compression.

The experiments showed that local buckling had little influence on the initial compression stiffness of the specimens, but it reduced the strength and ductility performance of the members. The buckling stress of the surface steel plates was significantly affected by the $B / t$ ratios. Theoretical equations based on the Euler curves were in good agreement with the experimental results and could be used for practical design.

FE models were also established to simulate the local buckling of DSC panels, and the effectiveness of these models was validated by comparison with the test results. Based on the parameter study, the effects of the shear stud arrangement, shear stud tension stiffness, and initial imperfections on the buckling behavior were evaluated. The FE analysis showed that shear studs in a staggered arrangement were more efficient than in a square arrangement, and more studies are necessary to improve understanding of the tension stiffness of the shear studs. 


\section{Acknowledgments}

The writers are grateful for funding from the National Science and Technology Major Project of the Ministry of Science and Technology of China (2011ZX06002-10), National Science Foundation of China (Award No. 51222810), and Beijing Natural Science Foundation (8122026).

\section{References}

[1] Wright HD, Oduyemi TOS, Evans HR. The design of double skin composite elements. J Constr Steel Res 1991; 19: 111-132. http://dx.doi.org/10.1016/0143-974X(91)90037-2

[2] Bruhl JC, Varma AH, Johnson WH. Design of SC composite walls for projectile impact: local failure. In: Transactions of 22nd Conference on Structural Mechanics in Reactor Technology (SMiRT-22), 2013.

[3] Mizuno J, Koshika N, Sawamoto Y, et al. Investigation on impact resistance of steel plate reinforced concrete barriers against aircraft impact Part 1: Test program and results. In: Transactions of 18th Conference on Structural Mechanics in Reactor Technology (SMiRT-18), 2005: 2566-2579.

[4] Takeuchi M, Narikawa M, Matsuo I, Hara K, Usami S. Study on a concrete filled structure for nuclear power plants. Nuclear Engineering and Design 1998; 179(2): 209-223.

[5] Amani M, Rafeei B, Alinia MM. Shear buckling and ultimate capacity of steel plates coupled with cover panels. J Constr Steel Res 2013; 80: 181-187. http://dx.doi.org/10.1016/j.jcsr.2012.08.002

[6] Akiyama H, Sekimoto H. A compression and shear loading tests of concrete filled steel bearing wall. In: Transaction of 11th Structural Mechanism Reactor Technology (SMiRT-11), 1991: 323-328.

[7] Wright HD. Buckling of plates in contact with a rigid medium. Structural engineer 1993; 71(12): 209-215.

[8] Wright HD, Oduyemi TOS, Evans HR. The experimental behavior of double skin composite elements. J Constr Steel Res 1991; 19(2): 97-110. 
[9] Clubley SK, Moy SSJ, Xiao RY. Shear strength of steel-concrete-steel composite panels: Part I - testing and numerical modeling. J Constr Steel Res 2003; 59 (6): 781-794.

[10] Nie JG, Ma XW, Tao MX, Fan JS, Bu FM. Effective stiffness of composite shear wall with double plates and filled concrete. J Constr Steel Res 2014; 99: 140-148. http://dx.doi.org/10.1016/j.jcsr.2014.04.001

[11] Sener KC, Varma AH. Steel-plate composite walls: Experimental database and design for out-of-plane shear. J Constr Steel Res 2014; 100: 197-210. http://dx.doi.org/10.1016/j.jcsr.2014.04.014

[12] Usami S, Akiyama H, Narikawa M, Hara K, Takeuchi M, Sasaki N. Study on a concrete filled steel structure for nuclear plants, Part 2: compressive loading tests on wall members. Proceedings of 13th Structural Mechanism Reactor Technology (SMiRT-13), August 13-18, Porto Alegre, Brazil; 1995: 21-26.

[13] Kanchi M. Experimental study on a concrete filled steel structure, compressive Tests (1). Summary of Technical Papers of Annual Meeting, Architectural Institute of Japan Conference - Part 2, 1996: 1071-1072.

[14] Miyauchi Y, Ozaki M, Doutan Y, Okiwara R, Usami D. Experimental study on a concrete-filled steel structure, compressive test (2). Summary of Technical Papers of Annual Meeting, Architectural Institute of Japan Conference - Part 2, 1996: 1073-1074.

[15] Choi BJ, Kim WK, Kim WB, Kang CK. Compressive performance with variation of yield strength and width-thickness ratio for steel plate-concrete wall structures. Steel and Composite Structures, 2013; 14(5): 473-491.

[16] Zhang K, Varma AH, Malushte SR, Gallocher S. Effect of shear connectors on local buckling and composite action in steel concrete composite walls. Nuclear Engineering and Design, 2014, 269: 231-239.

[17] Nie JG, Li FX. Study of the stability of steel-concrete composite plates under uniaxial compressed load. China Railway Science, 2009; 30(6): 27-32. (in Chinese) 
[18] Liang QQ, Uy B, Wright HD, Bradford MA. Local buckling of steel plates in double skin composite panel under biaxial compression and shear. J Struct Eng ASCE 2004; 130(3): 443-51.

[19] Liang QQ, Uy B, Richard LJY. Local buckling of steel plates in concrete-filled thin-walled steel tubular beam-columns. J Constr Steel Res 2007; 63:396-405.

[20] Pallarés L, Hajjar J. Headed steel stud anchors in composite structures, part II: tension and interaction. J Constr Steel Res 2010; 66(2): 213-228. http://dx.doi.org/10.1016/j.jcsr.2009.08.008 


\section{Table list:}

Table 1 Specimen parameters

Table 2 Material properties of steel plate

Table 3 Comparisons of axial stiffness during local buckling

Table 4 Calculated and tested strength of the specimens

Table 5 Buckling loads and stresses 


\section{Figure list:}

Fig. 1. Double skin composite panel specimens

Fig. 2. Stud arrangement

Fig. 3. Failure pattern of DSC6-240

Fig. 4. Failure pattern of DSC4-150/300

Fig. 5. Failure pattern of DSC4-300-150

Fig. 6. Failure pattern of DSC4-300X

Fig. 7. Load versus displacement measurements

Fig. 8. Buckling mode of surface plates

Fig. 9. Strain gauge arrangement

Fig. 10. Load versus vertical strains

Fig. 11. Relations between buckling stress and $B / t$

Fig. 12. Comparisons of test results and prediction equations

Fig. 13. Finite element model

Fig. 14. Calculated buckling modes of specimens

Fig. 15. Comparisons of experimental and numerical load-strain curves

Fig. 16. Comparison of buckling stresses

Fig. 17. Stress versus deformation relationship with different values of tensile stiffness coefficient

Fig. 18. Buckling stress versus $B / t$ relations by considering the effects of $\alpha_{\mathrm{st}}$

Fig. 19. Stud arrangements and buckling modes of surface plates

Fig. 20. FE results of buckling stress

Fig. 21. Effects of tensile stiffness of stud on buckling 
Table 1 Specimen parameters

\begin{tabular}{|c|c|c|c|c|c|}
\hline Specimen No. & $\begin{array}{l}\text { Steel thickness } \\
t(\mathrm{~mm})\end{array}$ & $\begin{array}{c}\text { Stud spacing } \\
B(\mathrm{~mm})\end{array}$ & $B / t$ ratio & Stud arrangement & $f_{\text {cu }}(\mathrm{MPa})$ \\
\hline DSC4-150 & 4 & 150 & 37.5 & square & 43.3 \\
\hline DSC4-200 & 4 & 200 & 50.0 & square & 35.9 \\
\hline DSC4-250 & 4 & 250 & 62.5 & square & 42.2 \\
\hline DSC4-300 & 4 & 300 & 75.0 & square & 39.6 \\
\hline DSC4-150/300 & 4 & $150 / 300$ & 75 & vertical rectangle & 34.5 \\
\hline DSC4-300/150 & 4 & $300 / 150$ & 37.5 & horizontal rectangle & 35.5 \\
\hline DSC4-300X & 4 & 300 & -- & staggered & 39.8 \\
\hline DSC6-240 & 6 & 240 & 40.0 & square & 42.5 \\
\hline DSC6-300 & 6 & 300 & 50.0 & square & 37.1 \\
\hline DSC6-360 & 6 & 360 & 60.0 & square & 39.7 \\
\hline
\end{tabular}

Note: $f_{\mathrm{cu}}=$ concrete cubic compressive strength determined by $150 \mathrm{~mm} \times 150 \mathrm{~mm} \times 150 \mathrm{~mm}$ specimens. 
Table 2 Material properties of steel plate

\begin{tabular}{cccc}
\hline Steel plate thickness $(\mathrm{mm})$ & $f_{\mathrm{y}}(\mathrm{MPa})$ & $\varepsilon_{\mathrm{y}}\left(10^{-6}\right)$ & $f_{\mathrm{u}}(\mathrm{MPa})$ \\
\hline 4 & 409.5 & 1988 & 525.5 \\
6 & 348.4 & 1691 & 484.4 \\
12 & 339.0 & 1646 & 493.1 \\
\hline
\end{tabular}


Table 3 Comparisons of axial stiffness during local buckling

\begin{tabular}{cccccccccccccc}
\hline Specimen No. & $N_{\mathrm{y}}(\mathrm{kN})$ & $\begin{array}{c}\delta_{\mathrm{y}} \\
(\mathrm{mm})\end{array}$ & $\begin{array}{c}N_{\mathrm{u}} \\
(\mathrm{kN})\end{array}$ & $\begin{array}{c}\delta_{\mathrm{u}} \\
(\mathrm{mm})\end{array}$ & $\begin{array}{c}N_{\mathrm{y}} / N_{\mathrm{u}} \\
(\mathrm{kN})\end{array}$ & $\begin{array}{c}N_{0.3 \mathrm{u}} \\
(\mathrm{mm})\end{array}$ & $\begin{array}{c}\delta_{0.3 \mathrm{u}} \\
(\mathrm{kN})\end{array}$ & $\begin{array}{c}N_{0.8 \mathrm{u}} \\
(\mathrm{mm})\end{array}$ & $\begin{array}{c}\delta_{0.8 \mathrm{u}} \\
(\mathrm{kN} / \mathrm{mm})\end{array}$ & $\begin{array}{c}K_{0.3 \mathrm{u}-\mathrm{y}} \\
K_{0.3 \mathrm{u}-0.8 \mathrm{u}} \\
(\mathrm{kN} / \mathrm{mm})\end{array}$ & $\begin{array}{c}K_{0.3 \mathrm{u}-0.8 \mathrm{u} /} \\
K_{0.3 \mathrm{u}-\mathrm{y}}\end{array}$ \\
\hline DSC4-150 & 7400 & -1.76 & 11249 & -3.57 & 0.66 & 3398 & -0.55 & 9004 & -2.27 & -3314 & -3268 & 0.99 \\
DSC4-200 & 4200 & -1.25 & 10318 & -3.91 & 0.41 & 3007 & -0.93 & 8201 & -2.37 & -3699 & -3601 & 0.97 \\
DSC4-250 & 5200 & -2.26 & 11230 & -4.67 & 0.46 & 3399 & -1.75 & 9004 & -3.27 & -3496 & -3687 & 1.05 \\
DSC4-300 & 4000 & -1.98 & 11610 & -5.11 & 0.34 & 3406 & -1.75 & 9392 & -3.66 & -2582 & -3122 & 1.21 \\
DSC4-150/300 & 4800 & -1.57 & 10122 & -4.48 & 0.47 & 3003 & -1.02 & 8001 & -2.78 & -3267 & -2836 & 0.87 \\
DSC4-300/150 & 7200 & -2.62 & 9452 & -4.24 & 0.76 & 2809 & -1.19 & 7607 & -2.77 & -3071 & -3032 & 0.99 \\
DSC4-300X & 4000 & -1.52 & 9474 & -4.76 & 0.42 & 2803 & -0.93 & 7605 & -3.30 & -2013 & -2026 & 1.01 \\
DSC6-240 & 9200 & -2.71 & 13525 & -4.68 & 0.68 & 3999 & -1.62 & 10803 & -3.20 & -4805 & -4307 & 0.90 \\
DSC6-360 & 5800 & -0.77 & 13033 & -3.75 & 0.45 & 3999 & -0.54 & 10407 & -2.01 & -7744 & -4374 & 0.56 \\
\hline
\end{tabular}


Table 4 Calculated and tested strength of the specimens

\begin{tabular}{ccccccc}
\hline Specimen No. & $N_{\mathrm{u}, \text { side }}(\mathrm{kN})$ & $N_{\mathrm{u}, \mathrm{c}}(\mathrm{kN})$ & $N_{\mathrm{u}, \text { cal }}(\mathrm{kN})$ & $N_{\mathrm{u}, \text { est }}(\mathrm{kN})$ & $N_{\mathrm{u}, \text { cal }} / N_{\mathrm{u}, \text { test }}$ & $N_{\mathrm{r}}(\mathrm{kN})$ \\
\hline DSC4-150 & 1953 & 9482 & 11434 & 11249 & 1.02 & 4718 \\
DSC4-200 & 1953 & 7860 & 9813 & 10318 & 0.95 & 4353 \\
DSC4-250 & 1953 & 9235 & 11188 & 11230 & 1.00 & 4467 \\
DSC4-300 & 1953 & 8664 & 10617 & 11610 & 0.91 & 4265 \\
DSC4-150/300 & 1953 & 7562 & 9515 & 10122 & 0.94 & 5746 \\
DSC4-300/150 & 1953 & 7769 & 9722 & 9452 & 1.03 & 6502 \\
DSC4-300X & 1953 & 8703 & 10656 & 9475 & 1.12 & - \\
DSC6-240 & 1953 & 9313 & 11266 & 13525 & 0.83 & 5297 \\
DSC6-300 & 1953 & 8126 & 10079 & 11606 & 0.87 & - \\
DSC6-360 & 1953 & 8690 & 10643 & 13033 & 0.82 & 6155 \\
\hline
\end{tabular}


Table 5 Buckling loads and stresses

\begin{tabular}{lcccc}
\hline \multicolumn{1}{c}{ Specimen No. } & Buckling Load $(\mathrm{kN})$ & Position & $\sigma_{\mathrm{v}}(\mathrm{MPa})$ & $\sigma_{0}(\mathrm{MPa})$ \\
\hline DSC4-150 & 7400 & A & -90.8 & 116.1 \\
DSC4-200 & 4200 & A & -47.6 & 49.7 \\
DSC4-250 & & B & -65.7 & 60.9 \\
& 5200 & A & -63.0 & 70.0 \\
DSC4-300 & 4000 & B & -28.5 & 61.7 \\
& & A & -30.2 & 29.8 \\
DSC4-150-300 & 4800 & B & -53.3 & 48.0 \\
& & A & -125.0 & 134.5 \\
DSC4-300-150 & 7200 & B & -99.3 & 109.6 \\
DSC4-300X & 4000 & A & -243.4 & 226.0 \\
DSC6-240 & 9200 & A & -49.3 & 84.6 \\
& & A & -138.1 & 144.9 \\
DSC6-360 & 5800 & B & -162.8 & 144.3 \\
& & A & -35.7 & 46.3 \\
& & B & -98.2 & 95.7 \\
\hline
\end{tabular}



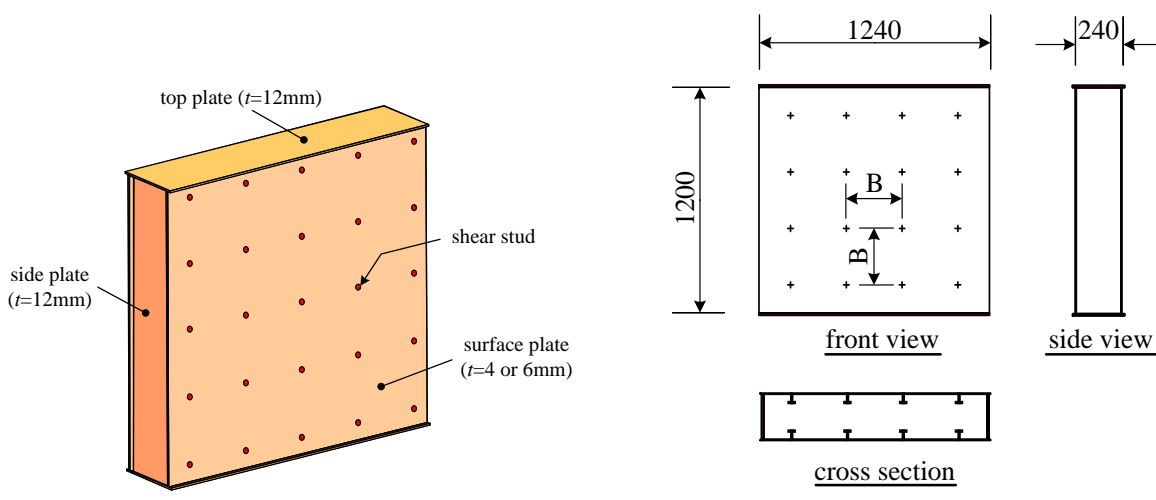

Fig. 1. Double skin composite panel specimens 


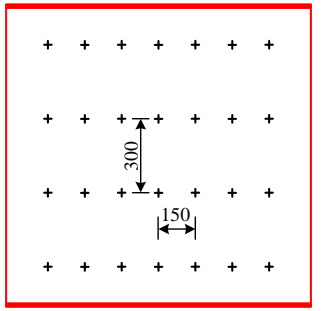

(a) Vertical rectangle (DSC-150/300)

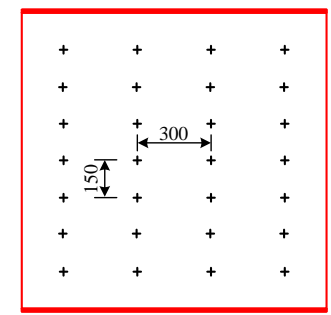

(b) Horizontal rectangle (DSC-300/150)

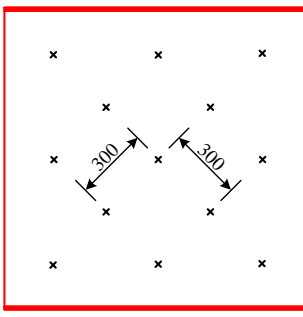

(c) Staggered (DSC4-300X)

Fig. 2. Stud arrangement 


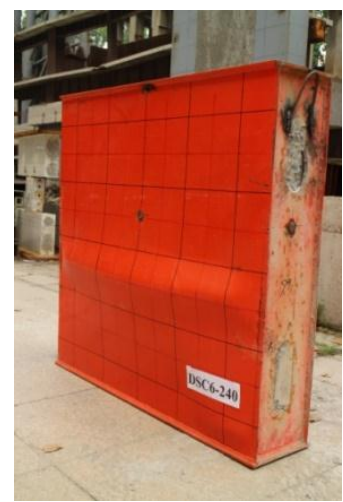

(a) Buckling mode (front)

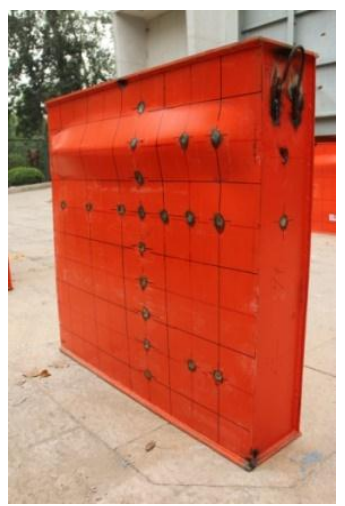

(b) Buckling mode (back)

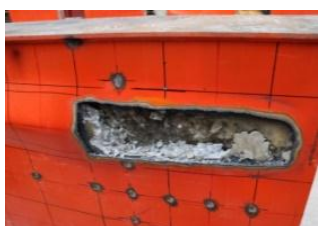

(c) Concrete crushing

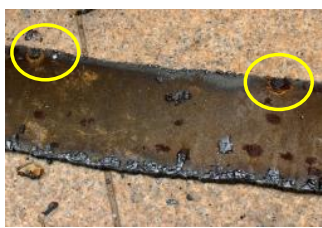

(d) Stud fracture

Fig. 3. Failure pattern of DSC6-240 

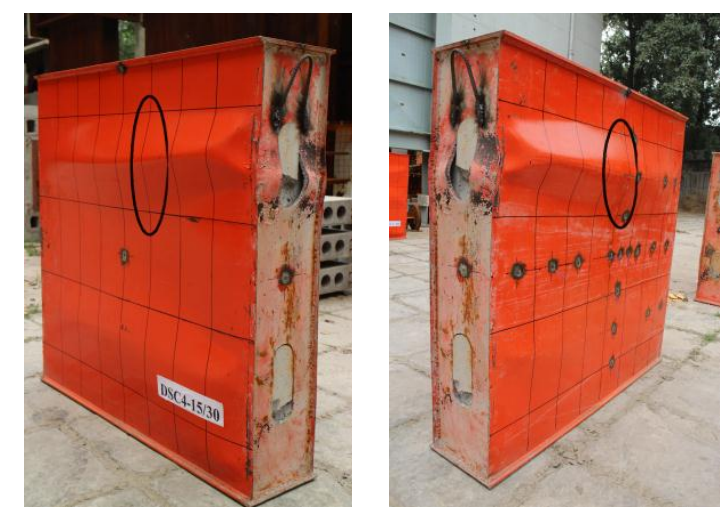

Fig. 4. Failure pattern of DSC4-150/300 

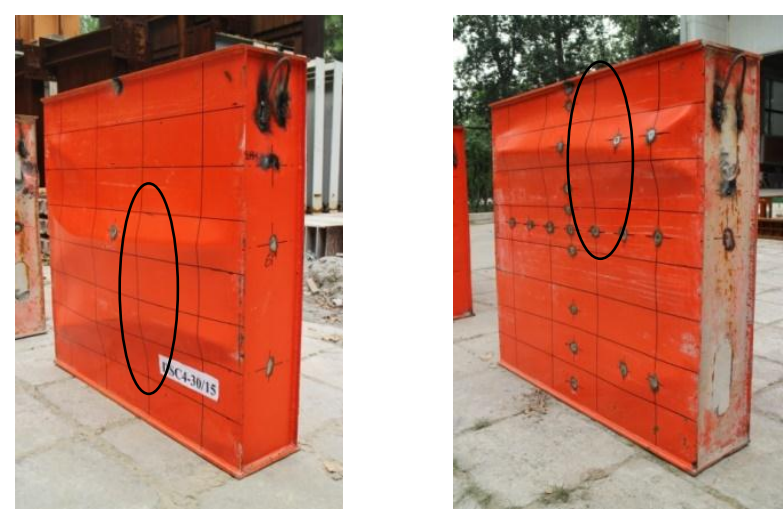

Fig. 5. Failure pattern of DSC4-300/150 

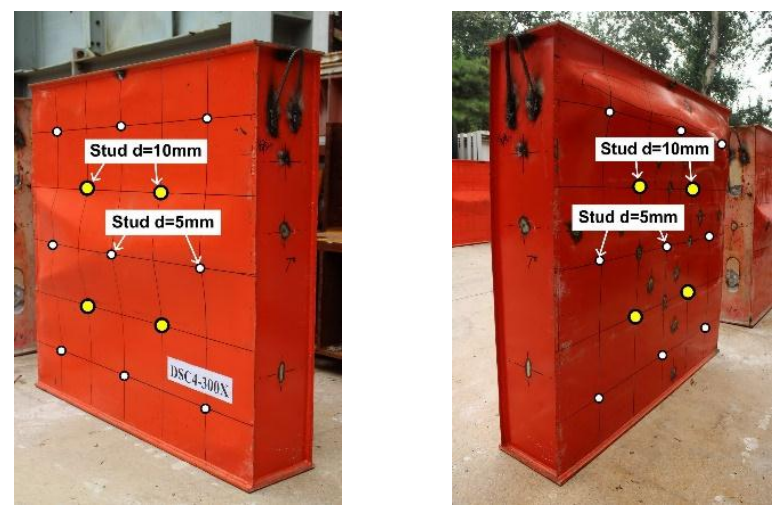

Fig. 6. Failure pattern of DSC4-300X 


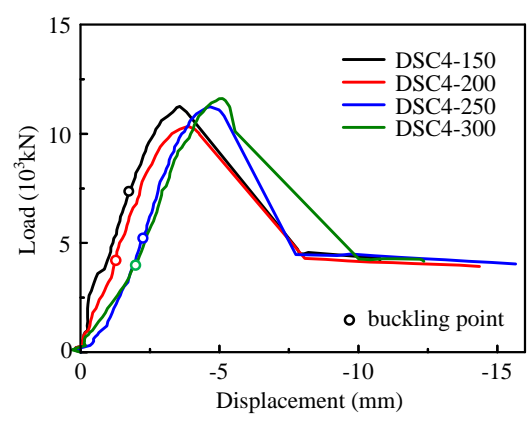

(a)

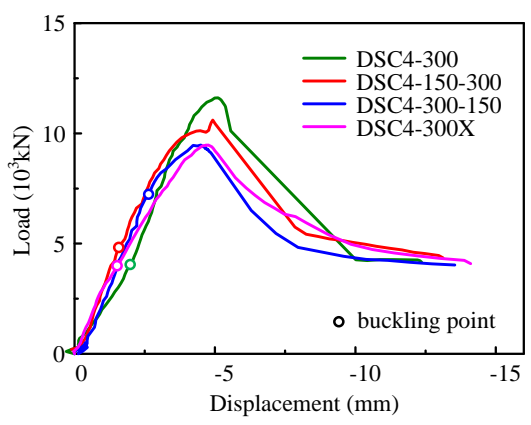

(b)

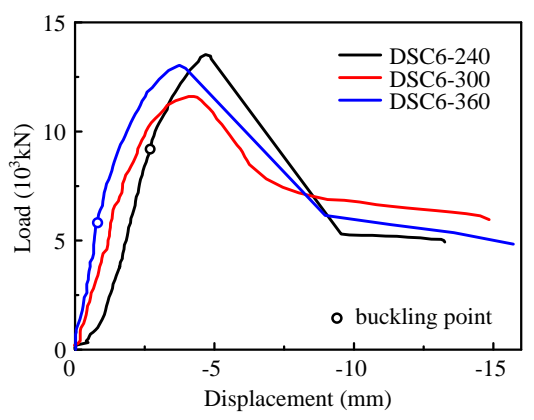

(c)

Fig. 7. Load versus displacement measurements 

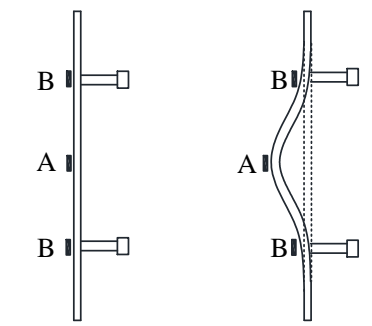

Before buckling After buckling

Fig. 8. Buckling mode of surface plates 


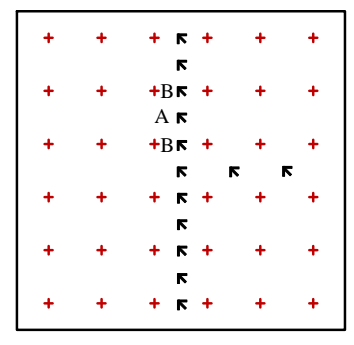

(a)

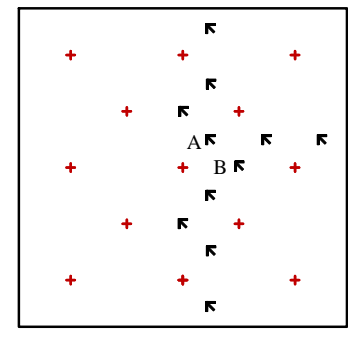

(b)

Fig. 9. Strain gauge arrangement 


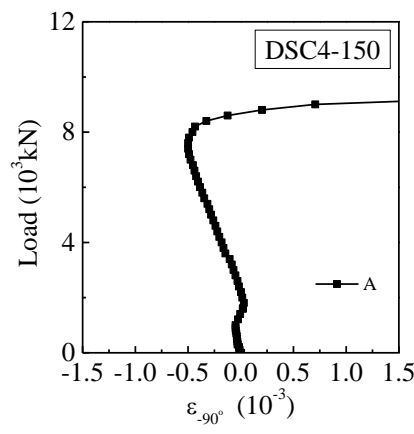

(a)

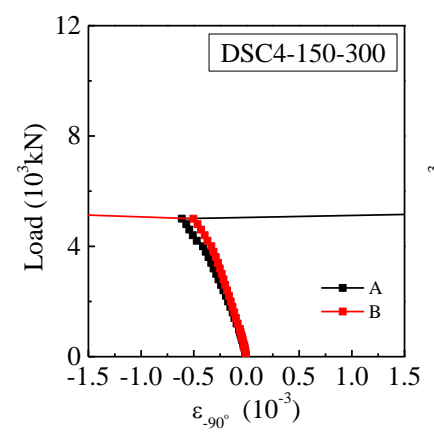

(e)

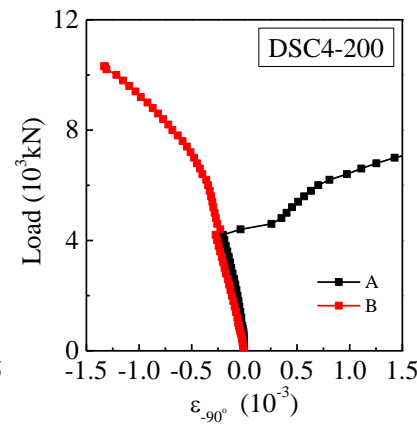

(b)

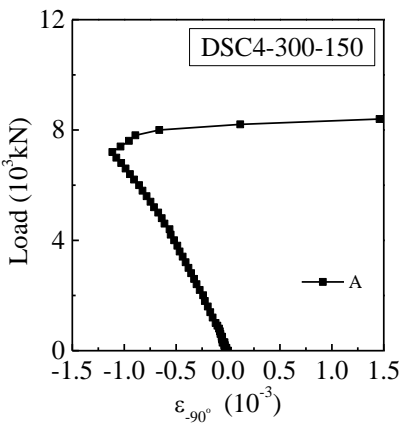

(f)

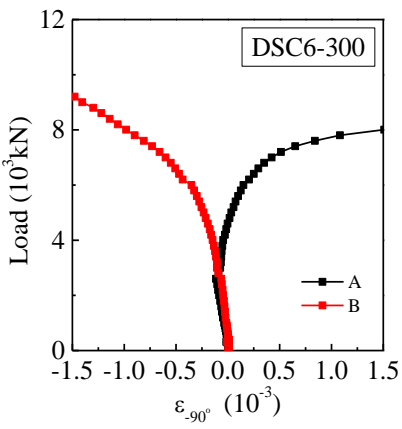

(i)

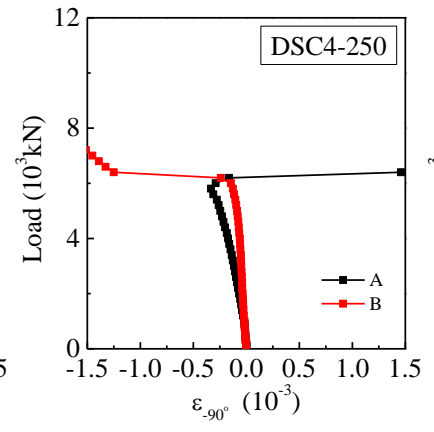

(c)

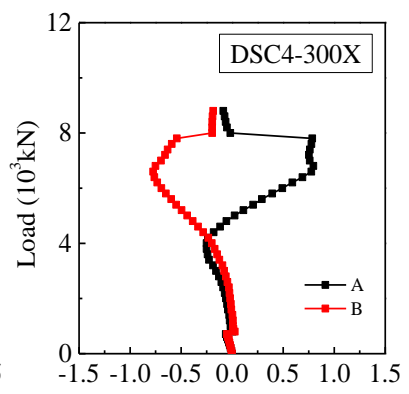

(g)

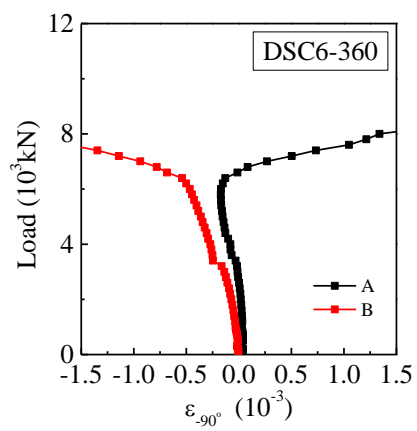

(j)

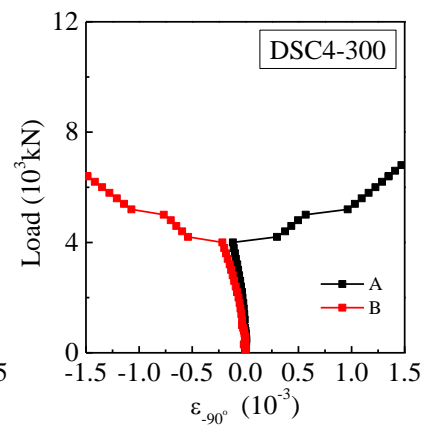

(d)

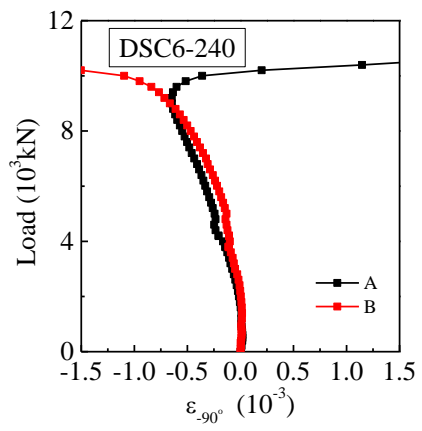

(h)

Fig. 10. Load versus vertical strains 


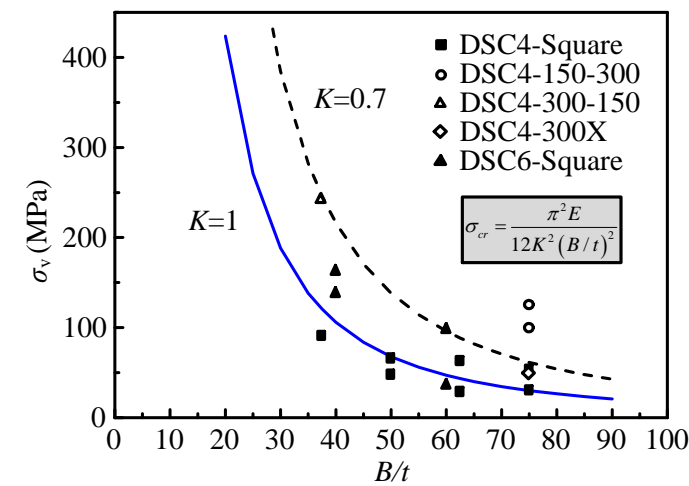

(a) Vertical stress

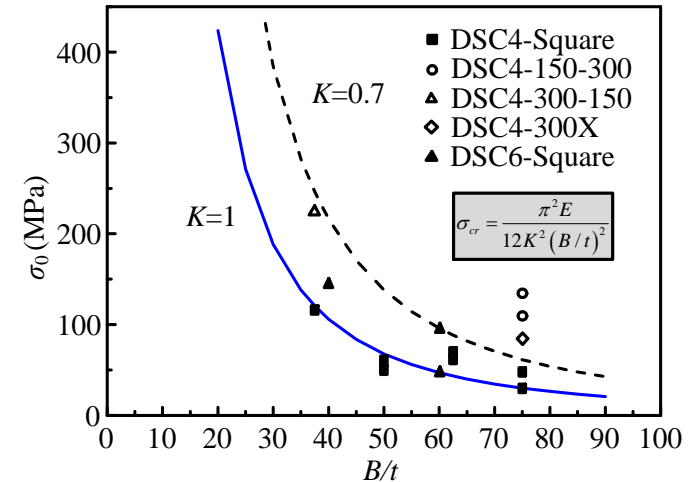

(b) von Mises stress

Fig. 11. Relations between buckling stress and $B / t$ 


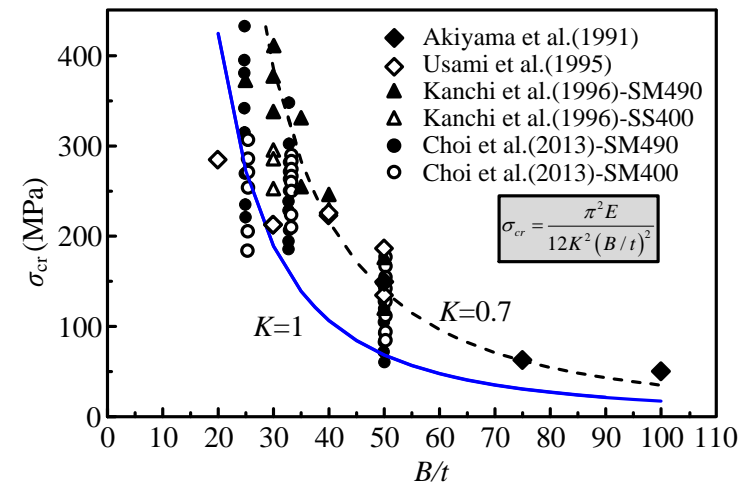

Fig. 12. Comparison of test results and prediction equations 


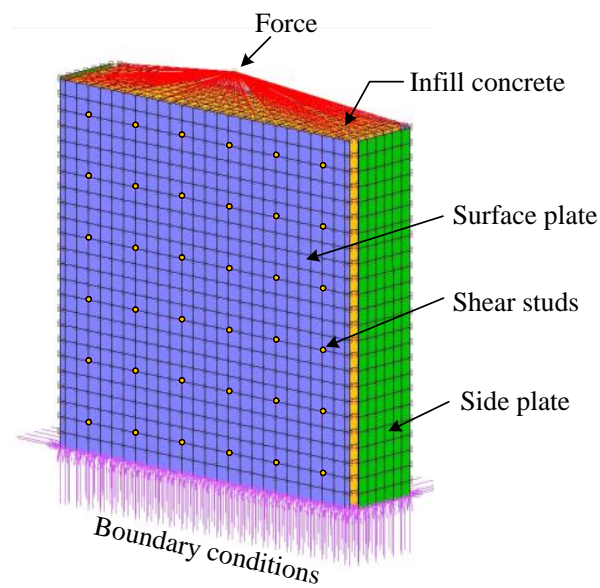

Fig. 13. Finite element model 

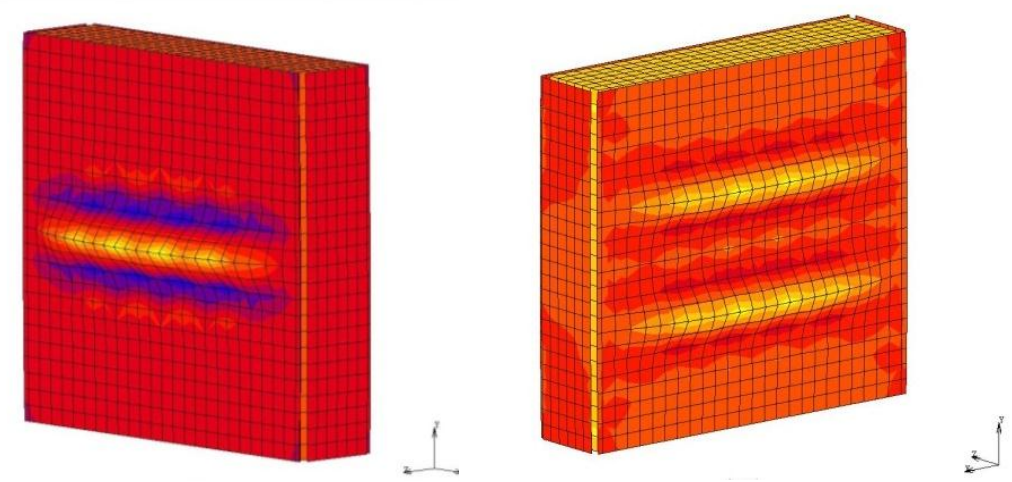

Fig. 14. Calculated buckling modes of specimens 

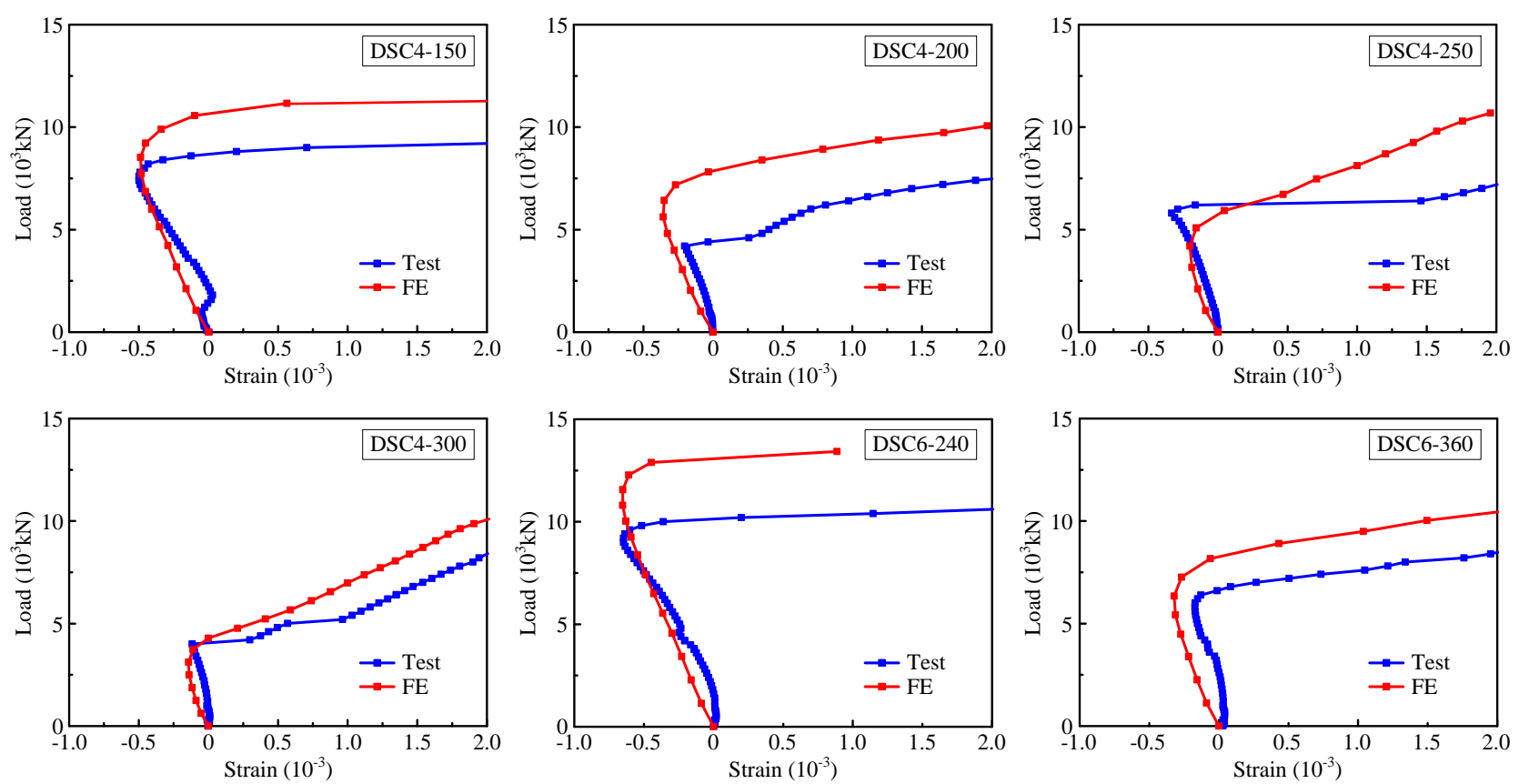

Fig. 15. Comparisons of experimental and numerical load-strain curves 


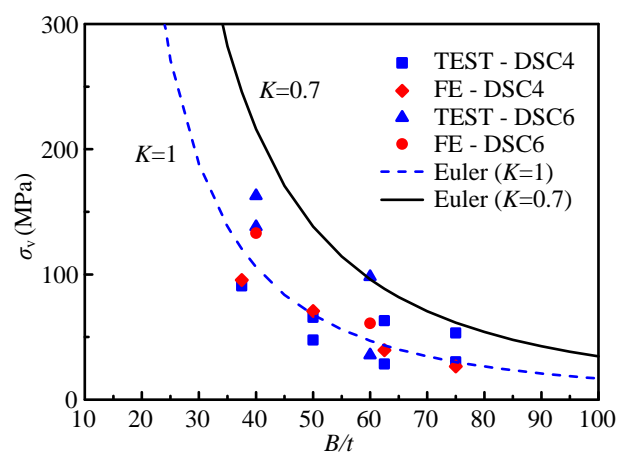

Fig. 16. Comparison of buckling stresses 


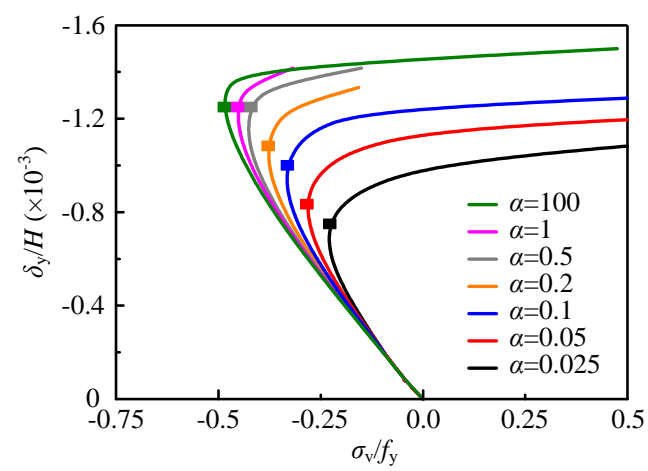

Fig. 17. Stress versus deformation relationship with different values of tensile stiffness coefficient 


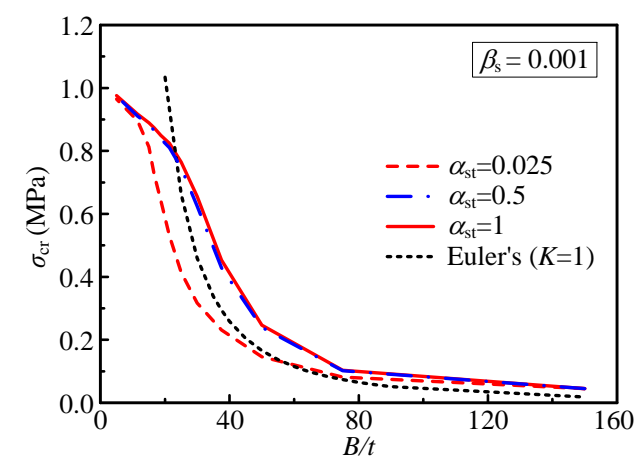

Fig. 18. Buckling stress versus $B / t$ relations by considering the effects of $\alpha_{\text {st }}$ 


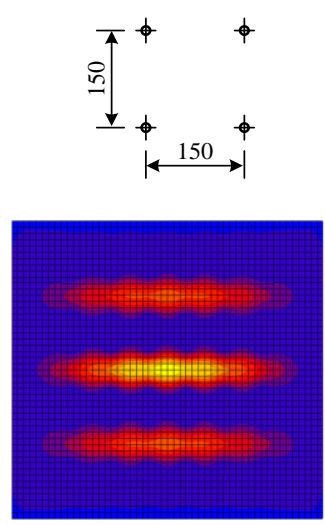

(a) FE150
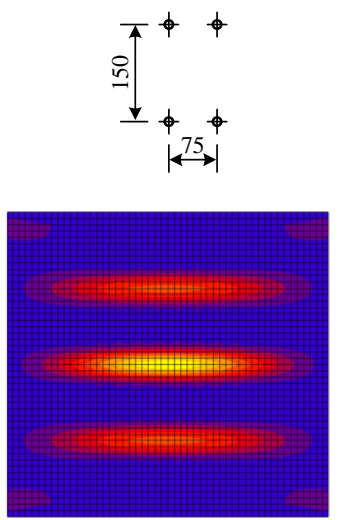

(b) FE475-150
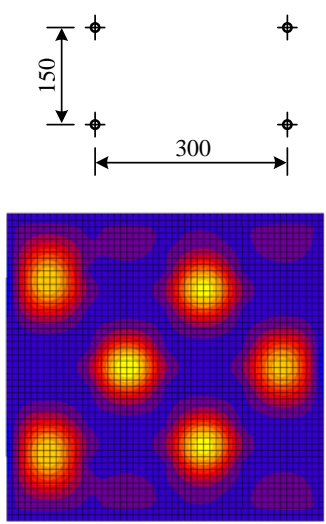

(c) FE300-150
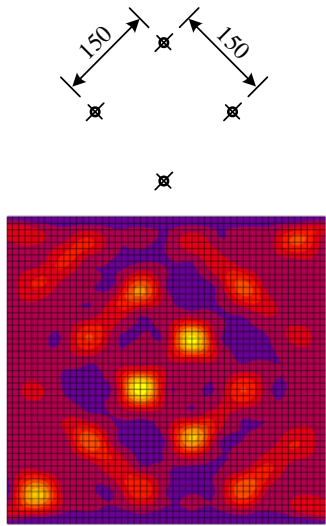

(d) FE150X

Fig. 19. Stud arrangements and buckling modes of surface plates 


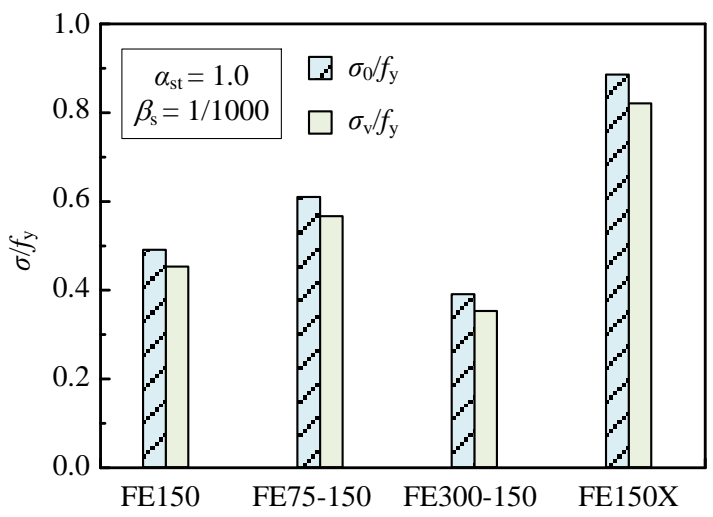

Fig. 20. FE results of buckling stress 


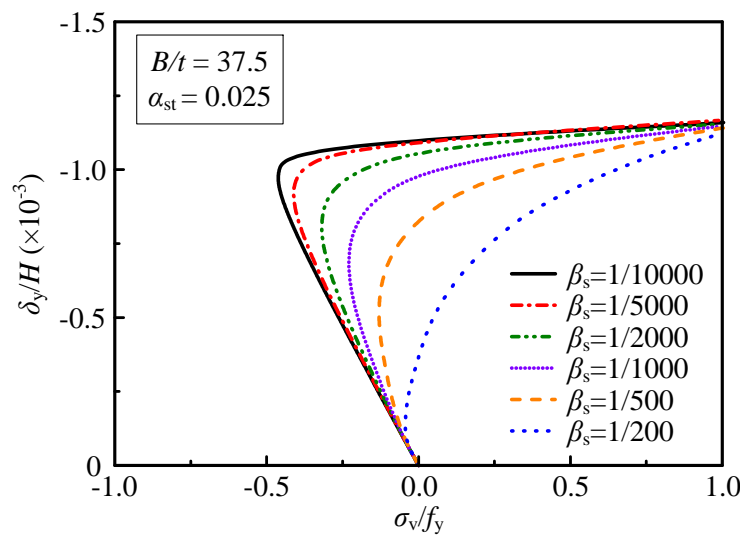

Fig. 21. Effects of tensile stiffness of stud on buckling 